\title{
The Role of Pancasila in Elementary Schools to Face the Challenges of the Disruption Era
}

\author{
Fara Diba Catur Putri \\ Univeritas Bhayangkara Raya, Jakarta, Indonesia \\ fara.diba@dsn.ubharajaya.ac.id
}

\section{Article History \\ accepted 23/03/2021}

approved 10/04/2021

\begin{abstract}
This study aims to determine the role of Pancasila in the era of disruption to be an important part that every individual must realize that this era must be passed and become a challenge in current developments. Changes that are increasingly fast are encouraging and requiring us to innovate. The ability to innovate is one strategy in maintaining our existence in this era. The development of this era has an impact on various existing fields, one of which is education. Education is an important aspect which is one of the means to achieve the national goals of the Indonesian nation. The method used is a qualitative descriptive case study research method for elementary school students in South Jakarta. The data source is elementary schools in Pasar Minggu sub-district. The research data is in the form of descriptions of the utterances of several informants who describe the role of Pancasila. The subjects of this study were elementary school students in Pasar Minggu sub-district with the object, namely 50 students and 10 class teachers. The results showed that the role of civic education for elementary school students and learning civics education is fun. Thus, creating a new paradigm even though the times are increasingly rapid, elementary school students still instill character values according to the noble culture of courtesy and ethics. The function of civic education is implemented in a habit of anticipating and overcoming moral crises in elementary school students in South Jakarta.
\end{abstract}

Keywords: disruption era, Pancasila, elementary school

\begin{abstract}
Abstrak
Penelitian ini bertujuan untuk mengetahui peran Pancasila dalam era disrupsi. Menjadi bagian penting yang harus disadari oleh setiap individu bahwa era ini harus dilalui dan menjadi tantangan dalam perkembangan saat ini. Perubahan yang semakin cepat semakin menggembirakan dan menuntut kita untuk berinovasi. Kemampuan berinovasi merupakan salah satu strategi dalam mempertahankan eksistensi kita di era ini. Perkembangan zaman ini berdampak pada berbagai bidang yang ada, salah satunya adalah pendidikan. Pendidikan merupakan aspek penting yang merupakan salah satu sarana untuk mencapai tujuan nasional bangsa Indonesia. Metode yang digunakan adalah metode penelitian studi kasus deskriptif kualitatif pada siswa sekolah dasar di Jakarta Selatan. Sumber data adalah Sekolah Dasar di Kecamatan Pasar Minggu. Data penelitian berupa deskripsi ungkapan beberapa informan yang mendeskripsikan peran Pancasila. Subjek penelitian ini adalah siswa Sekolah Dasar di Kecamatan Pasar Minggu dengan objeknya yaitu 50 siswa dan 10 guru kelas. Hasil penelitian menunjukkan bahwa peran Pancasila bagi siswa sekolah dasar dan pembelajaran pendidikan kewarganegaraan menyenangkan. Dengan demikian, menciptakan paradigma baru meskipun perkembangan zaman semakin pesat, siswa sekolah dasar tetap menanamkan nilai-nilai budi pekerti yang luhur sesuai dengan budaya sopan santun dan etika. Fungsi pendidikan kewarganegaraan diimplementasikan dalam kebiasaan mengantisipasi dan mengatasi krisis moral pada siswa sekolah dasar di Jakarta Selatan.
\end{abstract}

Kata kunci : era disrupsi, pancasila, sekolah dasar

Social, Humanities, and Education Studies (SHEs): Conference Series https://jurnal.uns.ac.id/shes

p-ISSN 2620-9284 e-ISSN 2620-9292 


\section{PENDAHULUAN}

Adanya kebijakan strategis dalam penyelenggaraan sektor pendidikan dengan membangun berbagai komponen di dalamnya untuk menghadapi era disrupsi saat ini. Sejalan dengan hal tersebut, pembelajaran merupakan komponen penting dalam pendidikan. Pembelajaran diartikan sebagai interaksi antara pendidik dan peserta didik dalam melaksanakan proses pendidikan. Dalam era disrupsi seperti sekarang ini, inovasi pembelajaran merupakan salah satu upaya yang dapat dikembangkan secara signifikan dalam pengembangan aspek pendidikan. Hal inilah yang menjadi dasar penulis untuk menyajikan pembahasan inovasi pembelajaran Pancasila di Sekolah Dasar sebagai upaya menghadapi tantangan era disrupsi dalam artikel ini. Pancasila memiliki peran strategis dalam membangun warga negara menjadi warga negara yang baik. Hal ini menunjukkan bahwa Pancasila sangat penting untuk diajarkan kepada siswa baik tingkat SD maupun perguruan tinggi. Karakteristik pembelajaran disesuaikan dengan tingkat kebutuhan siswa pada setiap jenjang sehingga pembelajaran yang dikembangkan memiliki keunikan tersendiri. Untuk itu, adanya era disrupsi menjadi tantangan besar bagi para pendidik yang mengajar Pendidikan Kewarganegaraan untuk dapat berinovasi dalam pembelajaran yang dikembangkan dengan berbagai upaya yang dilakukan. Pendidikan kewarganegaraan merupakan mata pelajaran wajib dan wajib dipelajari oleh anak-anak mulai dari sekolah dasar. Karena sangat penting bagi mereka untuk mengetahui dan memahami tentang bangsa dan negara Indonesia. Sehingga mereka dididik sejak kecil untuk memiliki rasa cinta tanah air yang tinggi dan memiliki kesadaran yang tinggi untuk menjaga kemerdekaan Indonesia yang telah diperjuangkan oleh para pahlawan bangsa yang berhasil mengusir penjajah. Jika pondasi yang baik sudah ditanam sejak kecil, maka akan tumbuh dengan baik kedepannya. Kita sebagai bagian dari bangsa Indonesia juga memiliki peran yang sama untuk menjaga dan mempertahankan dasar negara kita, Indonesia. Namun, yang terjadi akhir-akhir ini, persoalan kewarganegaraan seringkali dipandang sebelah mata oleh banyak pihak. Padahal, Pendidikan Kewarganegaraan atau yang sering disebut PKN merupakan mata pelajaran yang harus diberikan dengan baik agar anak paham. Masih banyak juga anak-anak jaman sekarang yang tidak hafal Pancasila, miris banget. Ini seharusnya tidak terjadi, jika pendidikan kewarganegaraan disampaikan dengan baik. Oleh karena itu, institusi pendidikan khususnya tenaga pengajar dituntut untuk dapat menyampaikan materi pendidikan kewarganegaraan secara jelas. Oleh karena itu, pendidikan kewarganegaraan sangat penting untuk disampaikan kepada anak-anak kita sejak dini. Tidak hanya sekolah dan lembaga pendidikan, keluarga juga berpengaruh dalam mendidik karakter dan kesadaran anak terhadap pendidikan nasional dan negara. Dengan begitu, kita bisa melahirkan caloncalon generasi bangsa yang baik dan bisa menjadikan Indonesia negara yang lebih baik.

Namun yang masih harus dilakukan Mendiknas adalah mengajak sekolahsekolah yang ada untuk memaksimalkan kualitas tenaga pengajarnya agar dapat menyampaikan materi Kewarganegaraan dengan baik kepada siswa dan kesadaran yang tinggi dari lembaga pendidikan untuk memprioritaskan pendidikan kewarganegaraan untuk Indonesia yang lebih luas. baik. Perlu kesadaran dari berbagai pihak untuk dapat mengubah keadaan ini. Oleh karena itu, mari kita bantu ciptakan generasi muda masa depan yang baik demi mewujudkan Indonesia yang lebih baik. Padahal pandemi akan menjadi daya tarik tersendiri untuk dilakukan secara aktif melalui pembelajaran online. Dalam kurikulum PKn materi yang terkandung di dalamnya diharapkan dapat memberikan pemahaman kepada peserta didik tentang informasi tentang kewarganegaraan, yang pada akhirnya dapat meningkatkan Kesadaran kewarganegaraan siswa dan selanjutnya mendorong siswa untuk berpartisipasi dalam kegiatan kewarganegaraan di lingkungan kecil seperti di sekolah 
dan di sekolah. lingkup yang lebih luas yaitu dalam kehidupan bermasyarakat, berbangsa dan bernegara.

Teori

Pelaksanaan pembelajaran Pendidikan Pancasila dan Kewarganegaraan (PKn) sangat penting dalam meningkatkan kesadaran kewarganegaraan peserta didik, karena jika dilandasi oleh tujuannya, PKn atau yang lebih dikenal dengan pendidikan kewarganegaraan mempunyai fungsi dan peran sebagai pendidikan kewarganegaraan. (Kariadi, 2017: 31), "Pendidikan Kewarganegaraan (Civic Education) merupakan mata pelajaran yang mengemban misi untuk membentuk kepribadian bangsa, yaitu sebagai upaya sadar dalam" pembangunan bangsa dan karakter ". Dalam konteks ini , peran PKn bagi kelangsungan hidup berbangsa dan bernegara sangat strategis. Negara yang demokratis pada akhirnya harus bertumpu pada ilmu, keterampilan dan keutamaan warganya serta yang dipilinnya untuk menduduki jabatan publik. Mempersiapkan peserta didik menjadi baik. warga negara (menjadi warga negara yang baik dan cerdas) yang memiliki komitmen kuat menjaga keberagaman di Indonesia dan menjaga keutuhan bangsa. Selanjutnya menurut (Budimansyah \& Suryadi, 2017: 31) "PKn merupakan bidang kajian yang melaksanakan misi mencerdaskan kehidupan bangsa ".

\section{METODE}

Jenis penelitian ini adalah studi kasus yang merupakan bagian dari metode kualitatif yang bermaksud untuk menggali suatu kasus tertentu secara lebih mendalam dengan melibatkan pengumpulan berbagai sumber informasi. Creswell mendefinisikan studi kasus sebagai eksplorasi sistem atau kasus terbatas. Ini merupakan kasus yang menarik untuk diteliti karena ciri-ciri khusus dari kasus tersebut memiliki makna bagi orang lain, setidaknya bagi peneliti. Studi kasus adalah studi tentang kekhususan dan kompleksitas satu kasus dan mencoba memahami kasus dalam konteks, situasi, dan waktu tertentu. Dengan metode ini diharapkan peneliti dapat menangkap kompleksitas kasus tersebut. Penelitian ini dilakukan karena kasusnya begitu unik, penting, bermanfaat bagi pembaca dan masyarakat pada umumnya. Dengan memahami kasus tersebut secara mendalam, peneliti akan memahami pentingnya kepentingan suatu organisasi komunitas atau komunitas tertentu. Untuk memperoleh data yang valid dan dapat dipertanggungjawabkan secara ilmiah maka peneliti menggunakan teknik pengumpulan data yaitu observasi yaitu perilaku yang terlihat dan tujuan yang ingin dicapai. Oleh karena itu peneliti melakukan observasi dan observasi langsung di lapangan sesuai sampel yang digunakan. Wawancara adalah pertemuan dua orang untuk saling bertukar informasi dan gagasan melalui tanya jawab, sehingga pemaknaan dapat terkonstruksi dalam suatu topik tertentu. Wawancara digunakan sebagai teknik pengumpulan data jika peneliti ingin melakukan studi pendahuluan untuk menemukan masalah yang harus diteliti, namun juga ingin mengetahui hal-hal yang lebih mendalam dari responden. Teknik pengumpulan data ini didasarkan pada laporan diri atau laporan diri, atau setidaknya pada pengetahuan dan / atau keyakinan pribadi. Dalam penelitian kualitatif data merupakan sumber teori atau teori yang didasarkan pada data. Kategori dan konsep dikembangkan oleh peneliti di lapangan. Data lapangan dapat digunakan untuk memverifikasi teori-teori yang muncul di lapangan dan terus disempurnakan selama proses penelitian dan dilakukan berulang kali. Analisis data bersifat terbuka dan induktif karena terbuka untuk perubahan, perbaikan dan penyempurnaan berdasarkan data yang baru dimasukkan.

\section{HASIL DAN PEMBAHASAN}

Adanya konfigurasi atau kerangka sistematis pendidikan kewarganegaraan dibangun berdasarkan paradigma secara kurikuler yang dirancang sebagai mata pelajaran pembelajaran yang bertujuan untuk mengembangkan potensi individu menjadi warga negara Indonesia yang berakhlak mulia, cerdas, partisipatif, dan bertanggung jawab. Pendidikan kewarganegaraan secara teoritis dirancang sebagai 
mata pelajaran yang mengandung dimensi kognitif, afektif, dan psikomotorik yang bertautan atau saling menembus dan terintegrasi dalam konteks substansi gagasan, nilai, konsep dan moral Pancasila, kewarganegaraan demokratis, dan bernegara. pertahanan. Pada era sekarang, tujuan pendidikan hendaknya tidak hanya bertumpu pada penguatan kognitif peserta didik, akan tetapi penguatan afektif dan psikomotorik juga harus dimiliki peserta didik sebagai hasil dari proses pendidikan kewarganegaraan yang dirancang sebagai mata pelajaran yang menekankan pada konten yang membawa nilai-nilai (konten). menanamkan nilai) dan pengalaman belajar berupa berbagai perilaku yang perlu diwujudkan dalam kehidupan sehari-hari dan merupakan tuntutan hidup warga negara dalam kehidupan bermasyarakat, berbangsa, dan bernegara sebagai penjabaran lebih lanjut dari gagasan, nilai, konsep dan moral Pancasila. , kewarganegaraan demokratis dan pertahanan negara. Pengembangan kurikulum K-13 (Kurikulum 2013) dimana kurikulum tidak hanya fokus pada pengetahuan saja, tetapi sikap dan keterampilan. Penilaian ini digunakan untuk semua mata pelajaran. Untuk itu, diperlukan kerjasama antara guru dan siswa demi peningkatan karakter. Dalam pembelajaran di sekolah tentunya guru harus mampu menerapkan strategi atau model pembelajaran yang menarik untuk membangun semangat siswa dalam belajar. Tujuan guru tidak hanya untuk membuat siswa cerdas, tetapi untuk membentuk sikap mereka ke arah yang lebih baik. Jika anak sudah memiliki sikap yang baik maka akan lebih mudah baginya untuk menerima ilmu yang disampaikan kepada gurunya.

Guru harus mampu mengemas proses pembelajaran menjadi inovatif. Pembelajaran inovatif terdiri dari pendekatan yang berpusat pada siswa, multi model dan metode, multimedia, multi sumber belajar, pembelajaran kontekstual, evaluasi berbasis kognitif, afektif dan psikomotor, kedudukan guru sebagai pengarah. belajar. Pembelajaran inovatif dilakukan untuk meningkatkan karakter dan menjadikan pembelajaran lebih bermakna. Dalam menyusun pembelajaran, guru juga harus memperhatikan RPP berbasis karakter (Rencana Pelaksanaan Pembelajaran) dengan memperhatikan 11 nilai karakter yang dirumuskan oleh Kementerian Pendidikan Nasional (Setiawan, 2012) yang meliputi pengabdian, kejujuran, disiplin, demokrasi. , keadilan, tanggung jawab, cinta tanah air, orientasi. pada kesempurnaan, gotong royong, saling menghormati, dan bersedia berkorban. Kesebelas nilai tersebut harus ada dalam setiap tujuan pelaksanaan pembelajaran agar karakter peserta didik dapat terbentuk. Industri 4.0 disebut sebagai revolusi digital atau era disrupsi teknologi, yaitu pemanfaatan teknologi dari berbagai bidang terutama bidang pendidikan seperti gadget atau smartphone. Artinya revolusi industri dijadikan tantangan dan pemanfaatan. Revolusi industri 4.0 dikatakan menjadi tantangan jika penggunaan teknologi disalahgunakan oleh siswa sekolah dasar. media sosial seperti facebook, whatsapp, youtube, instagram, dan lainnya. Kenyataannya siswa sekolah dasar di era kekacauan sekarang ini sering memposting kalimat dan foto serta video yang tidak baik, hal ini disebabkan oleh degradasi etika dan penyimpangan nilai-nilai moral. Berbeda dengan pemanfaatan teknologi di era disrupsi jika digunakan sebagai alat bantu dalam proses pembelajaran. Jaman dapat berkembang, betapapun indahnya zaman, tetap menjunjung tinggi nilai-nilai moral dan menanamkan pada diri siswa agar dapat mengamalkannya dalam kehidupan sehari-hari. Bahkan jika satu nilai moral tidak diterapkan maka karakter siswa akan merosot bahkan tidak memiliki moral lagi.

Penyelenggaraan pendidikan pancasila di Indonesia saat ini harus terus ditingkatkan meskipun menghadapi kendala dan bobot yang cukup sulit. Pendidikan PKn di sekolah masih sangat membutuhkan peningkatan. Pendidikan sekolah dasar memiliki kualitas yang terbatas, baik yang dikelola oleh pemerintah maupun swasta, sehingga tidak tersedia lulusan yang memadai untuk penyelenggaraan pendidikan PKn yang komprehensif dan berkualitas. Hal ini membawa konsekuensi bahwa bukan tidak mungkin terdapat sejumlah mahasiswa yang berkualitas, akan tetapi mayoritas 
mahasiswa sebagai calon kader bangsa atau warga negara, kualitasnya belum dapat dijamin mengisi dan melaksanakan berbagai keberagaman. pekerjaan dan profesi dalam satu masyarakat abad ke-21.

\section{SIMPULAN}

Era disrupsi hendaknya dijadikan peluang bagi para pendidik khususnya guru untuk meningkatkan kemajuan pendidikan. Pendidikan Pancasila berbasis digital hendaknya tidak menjadi bencana, melainkan tantangan yang harus diselesaikan dan berusaha menjadikan tantangan tersebut sebagai peluang dalam pendidikan yang lebih berkompeten, khususnya dalam peningkatan karakter siswa sekolah dasar yang dilandasi nilai-nilai moral. Kemajuan teknologi harus dapat dimanfaatkan dengan baik dan tetap memperhatikan nilai-nilai moral agar nantinya peserta didik dapat menjadi generasi penerus bangsa yang cerdas, terampil dan berkarakter. Membentuk karakter siswa sekolah dasar yang berlandaskan nilai-nilai moral di era disrupsi dapat menjadikan siswa sebagai generasi yang akan terus mengindahkan nilai-nilai Pancasila untuk menjadi pedoman bangsa Indonesia sepanjang zaman dan tidak ketinggalan zaman. dibelakang oleh kemajuan teknologi yang terus berkembang dari waktu ke waktu.

\section{DAFTAR PUSTAKA}

Agustrian, Nyimas Lisa. (2017). Management of the Life Skill Program at the A/HafidzCity Halfway House.

Azizan, Nashran. 2017. Strengthening Pancasila Values in Elementary School Students. The paper was presented at the Annual National Seminar of the Faculty of Social Sciences with the theme"Education of National Social Sciences. Medan: Hotel Arya Duta Medan 20 October 2017. Bengkulu. Journal of Community Development. Volume 1. Number 1.

Creswell, John W., (2003). Research Design: Qualitative, Quantitative, and Mixed Methods Approaches. London: Sage Publications.

Fibriana, Rosania Mega. (2018). Citizenship Education as a Vehicle for Learning Defense Statefor Kahuripan Kediri University Students. Koulutus Journal:Education Journal Kahuripan. Volume 1. Number 1.

Hermann, M., Pentek, T., \& Otto, B. 2016. Design Principles for Indonesia 4.0 Scenarios. Presented at the 49 Hawaiian International Conference on Systems Science.

Ibda, Hamidulloh. 2018. Strengthening New Literacy in Madrasah Ibtidaiyah Teachers in Responding to the Challenges of the Industrial Revolution Era 4.0. Journal of Research and Thought Of Islamic Education, (Online). Vol.1 No.12018.

Isep. (2013). The Role of Citizenship Education as Legal Education in Seeking Legal Internalization Among Students. Journal of Educational Research. Volume 13. Number 1.

Kariadi, Dodik. (2017). Generations with global insight with local characteristics through the harmonization of cosmopolitan values and nationalism in the learning of Pkn. Pancasila and Journal Citizenship.Volume 1. Number 2.

Keer, David. (1999). Citizenship Education: An International Comparison. England: National Foundation for Educational Research-NFER.

Kosasih, Djahiri. et al. 1997. Guidelines for Teaching Pancasila and Citizenship Education. Jakarta: Balai Pustaka.

Lickona. (1992). Educating From Character How Our School Can Teach Respect and Responsibility. New York-Toronto-London-Sidney-Auckland: Bantan Books.

Nurizka, Rian., And Abdul Rahim. (2019). Student Character Building Through Classroom Management. Journal of Bhineka Tunggal Ika: Study of Civics Theory and Practice. Volume 6, No.2, November 2019, pp. 189-198.

Pemerintah Republik Indonesia. (2002). Undang-Undang Republik Indonesia Nomor 3 Tahun 2002 tentang Pertahanan Negara. 
Pemerintah Republik Indonesia. (1945). Undang-Undang Republik Indonesia Pasal 30 Ayat 1 \& 2 Tahun 1945 tentang Bela Negara Bagi Seluruh Rakyat Indonesia.

Quigley, CN, Buchanan, Jr. JH, Bachmueller, CF (1991). Civitas: A Framework for Civic Education. Calabasas: CCE.

Suwarno W. (2011). Implementation of State Defense to Achieve Nationalism. Civis Scientific Journal. Volume 1. Number 1.

Sulkipani. (2017). Citizenship Education Lesson Planning (Civics) toDevelop Students' State Defense Awareness. Civics Journal. Volume 14. Number 1.

Supriyanto, Anton. (2018). Efforts to Increase Courage in Opinion and Learning Achievement through the Application of the Moral Dilemma Model of PPKn Subjects. Journal of Bhineka Tunggal Ika: Study of Civics Theory and Practice. Volume 5, No.2, November 2018, pp. 116-122. 